Journal of Applied Pharmaceutical Science Vol. 7 (02), pp. 101-105, February, 2017

Available online at http://www.japsonline.com

DOI: 10.7324/JAPS.2017.70212

ISSN 2231-3354 (cc) BY-NC-sA

\title{
Toxicity of four novel Polyhedral Oligomeric Silsesquioxane (POSS) particles used in anti- cancer drug delivery
}

\author{
Abdulmajeed Almutary*, Barbara Sanderson \\ Medical Biotechnology, School of Medicine, Nursing and Health Sciences, Flinders University, Adelaide, Australia.
}

\begin{tabular}{|c|c|}
\hline ARTICLE INFO & ABSTRACT \\
\hline $\begin{array}{l}\text { Article history: } \\
\text { Received on: } 28 / 10 / 2016 \\
\text { Accepted on: } 04 / 12 / 2016 \\
\text { Available online: } 27 / 02 / 2017\end{array}$ & $\begin{array}{l}\text { The wide use of nanomaterials in medicine and especially in drug delivery had heightened the demand for a safe } \\
\text { use of nanoparticles (NPs) before delivered to patients. NPs are used to reduce the toxicity of some drugs; } \\
\text { however, the nanocarriers themselves impose risk on the patient health. The creation of NPs safe use guidelines } \\
\text { is based on experimental investigation on human cell lines to eliminate the risk of newly synthesized NPs. In }\end{array}$ \\
\hline $\begin{array}{l}\text { Key words: } \\
\text { Polyhedraloligomeric } \\
\text { silsesquioxane, POSS, } \\
\text { nanocarriers, toxicity, } \\
\text { HaCaT, anti-cancer, drug } \\
\text { delivery. }\end{array}$ & $\begin{array}{l}\text { diphenyltetrazolium bromide (MTT), and crystal violet assays and exposed for } 1,24 \text { and } 48 \mathrm{~h} \text { to human skin } \\
\text { keratinocytes (HaCaT). Five concentrations investigated ranging between }(0.001-100 \mathrm{mg} / \mathrm{mL} \text { ) for each particle } \\
\text { (size } 100 \mathrm{~nm} \text { in diameter). TrisilanolIsooctyl POSS particles significantly reduced the metabolic activity and } \\
\text { relative cell number of HaCaTcells lines after } 24 \mathrm{~h} \text { exposure. Trisilanol Phenyl, Cyclopentyl and Cyclohexal } \\
\text { POSS particles did not show any sign of toxicity; therefore, toxicity may attributed to the shape of the particle. } \\
\text { Trisilanol Phenyl, Cyclopentyl and Cyclohexal POSS particles show a promising application in anti-cancer drug } \\
\text { delivery. }\end{array}$ \\
\hline
\end{tabular}

\section{INTRODUCTION}

Nanotechnology is the science that involve the synthesis, design, characterization and application of devices and materials whose smallest function in at least one dimension is on the nanometre scale up or one billionth of a meter (Silva, 2004). At these scales, it is important to consider the individual molecule and interacting groups of molecules in relation to the properties of bulk macroscopic materials and devices (Silva, 2004). Because it is on a small scale, the properties of materials such as magnetism, color and ability to regulate electricity may be tailored to desired end user applications (Grassian, 2008). This resulted in different characteristics that could produce a wide range of novel products (Grassian, 2008). Nanotechnology applications cover communications, electronics, cosmeceutical, food, energy, and agricultural industries among others (Wilkinson, 2003). Currently, nanomaterials are used in environmental remediation, medical devices and pharmaceutical

* Corresponding Author

E-mail:almu0047@ flinders.edu.au areas giving scientists a chance to modify matter in varies parts of work and life (Martin, 1994). Some of the important applications in the field of medicine is in drug delivery, fluorescent biological labels, bio-detection of pathogens, detection of proteins, tissue engineering, tumour destruction, separation and purification of cells and molecules (Salata, 2004). Nanoparticles (NPs) are in the same size domain as proteins making it suitable for labelling and bio tagging. This property is underutilised currently for biological tagging (Salata, 2004). NPs could be attached with biological or molecular layer to act as biological interface such as antibodies, collagen or monolayers that are able to make nanoparticles biocompatible. Polyhedral oligomeric silsesquioxane (POSS) nanostructures have potential interest in many biomedical applications such as dental composites, drug delivery, biomedical devices, biosensors and tissue engineering (Ghanbari et al., 2011a). Cytocompatibility and non-toxicity are the features for making POSS suitable for biomedical applications (Gao et al., 2012; Jain and Bar-Shalom, 2014).

One of the major applications of POSS is its use in the development of cardiovascular implants. The incorporation of POSS with biocompatible polymers leading to the development 
of nanocompsoite materials that enhanced antithrombogeneicity, hemocompatibiltiy; reduce inflammatory response and calcification resistance (Ghanbari et al., 2011c). Currently, POSS containing polymers are under intensive investigations to develop a new generation of cardiovascular implants such as bypass grafts, heart valve prosthesis and coronary stents. In the meanwhile, there is a demand for more investigation on POSS NPs cytotoxicity for human cell lines (Singh et al., 2010). In this study, we evaluate the potential cytotoxicity of four novel POSS carriers. Toxicity of Trisilanol ethyl, trisilanolisooctyl, trisilanol phenyl, trisilanolcyclopentyl and trisilanolcyclohexyl POSS NPsafter exposure to human skin keratinocytes ( $\mathrm{HaCaT}$ ) was determined by 3- (4,5-dimethylthiazol-2-yl)-2,5-diphenyltetrazolium bromide (MTT), and crystal violet assays.

\section{MATERIALS AND METHODS}

\section{Reagents and NPs}

All reagents were purchased from Sigma Aldrich, Australia unless otherwise stated. These included, [3- (4,5dimethylthiazol-2yl)-diphenyltetrazolium bromide] MTT, The culture media used was Roswell Park Memorial Institute (RPMI) with $10 \%$ heat-inactivated fetal bovine serum (FBS) (HYQ ${ }^{\circledR}$, Hyclone, Utah, USA), penicillin and streptomycin. Millipore Milli-Q water with resistivity $=18.2 \mathrm{M} \Omega . \mathrm{cm}$ was used for all the experiments. POSS particles were synthesised by the Department of Chemical and Physical Sciences, Flinders University in South Australia and the physical and chemical properties mentioned in our previously published study (Almutary and Sanderson, 2016).

\section{Cell Culture}

$\mathrm{HaCaT}$ cell line was obtained from American Type Culture Collection (ATCC). Cells were grown in RPMI medium with $10 \%$ fetal bovine serum (FBS) and incubated at $37{ }^{\circ} \mathrm{C}, 5 \%$ $\mathrm{CO}_{2}$ in a humidified incubator. The cells growth started from $2 \times 10^{6}$ cells $/ \mathrm{ml}$ and subcultured when confluence reached $60-70 \%$ every 2-3 days.

\section{For Toxicity Assays}

$\mathrm{HaCaT}$ cells were seeded at 10,000 cells/well in a 96-flat plate then incubated for 18 hours to allow adherence. POSS particles were diluted in fresh medium. After incubation, cells were treated with five POSS particles range between (0.001$100 \mathrm{mg} / \mathrm{mL}$ ) for 1,24 and $48 \mathrm{~h}$. The solution was removed and the cells were washed twice with phosphate buffered saline (PBS) twice to remove excess POSS residue.

\section{3-(4,5-Dimethylthiazol-2-yl)-2,5-Diphenyltetrazolium Bromide Assay Experimental Procedure}

The toxicity of POSS particles determined by MTT assay as described (Mosmann, 1983). $1 \times 10^{4}$ cells were seeded in volume of $100 \mu 1$ into 96 -well flat bottom plate. MTT was added to each well at $0.5 \mathrm{mg} / \mathrm{mL}$, and then plates were incubated at $37{ }^{\circ} \mathrm{C}$ for $4 \mathrm{~h}$, then $80 \mu \mathrm{l}$ of $20 \%$ SDS in $0.02 \mathrm{M} \mathrm{HCl}$ was added to each well.
The plates were kept in the dark at room temperature for overnight. OD was read on ELISA reader at $570 \mathrm{~nm}$, with $630 \mathrm{~nm}$ as reference wave length. In each experiment a standard curve was run to convert the OD values to cells/well.

\section{Crystal Violet Assay}

HaCaT Cells were stained with crystal violet after exposed to particles. Live cells remained adhered to the plate and dead cells were washed away (Smith et al., 2016, Chiba et al., 1998). Three replicate plates were performed for cell count using crystal violet assay, each plate included 6 technical replicate wells per treatment. After exposure (see above), the plates were washed and $50 \mu 1$ of crystal violet stain was added and incubated at room temperature for 15 minutes. Then, the Stain was washed off with demineralized water and the plates were left to dry overnight. A $33 \%(\mathrm{v} / \mathrm{v})$ acetic acid was added to dissolve the stain and the absorption was read using microplate reader at $570 \mathrm{~nm}$. The results were expressed as percentage viability compared to untreated control.

\section{Statistical Analysis}

The data were expressed as mean $+/$ - SD of at least three independent experiments using one-way analysis of variance (ANOVA) and Tukey-Kramer multiple comparisons test using SPSS software to compare exposure groups. All comparisons were considered significant level $p<0.05$.

\section{RESULTS AND DISCUSSION}

Toxicity of POSS particles was investigated using two classical colorimetric assays. TrisilanolCyclohexyl, Cyclopentyl and Phenyl POSS particles did not interrupt the metabolic activity of HaCaT cell line. However, TrisilanolIsooctyl POSS particle after $24 \mathrm{~h}$ exposure significantly reduced the cell growth by $75 \%$ compared to untreated control. Interestingly, $4 \mathrm{~h}$ exposure to TrisilanolIsooctyl POSS increased the cell growth by 50\% compared to untreated control Fig.1. Due to POSS particles excellent compatibility with most monomers and polymers, functionalized POSS molecules can be easily incorporated into a variety of polymers (Ghanbari et al., 2011c). The main characteristic in POSS particles is the biocompatibility which resulted from the solid nature and low inflammatory reaction in the centre of the silicon reach area (Ghanbari et al., 2011a). In addition, non-toxicity and cytocompatibility are other features of POSS particles, therefore it a common used particles in biomedical applications (Kim et al., 2007). Several mechanisms are the cause of most of NPs toxicity; however, most intracellular and in vivo toxicity is a result of high level of reactive oxygen species (ROS) (Foldbjerg et al., 2009; El Badawy et al., 2010; Chang et al., 2012; Buonocore et al., 2010). For example, oxidative stress induced by NPs happen during the dissolution of iron-based NPs, in which stimulate ROS generation and form radicals from $\mathrm{H}_{2} \mathrm{O}_{2}$ (Auffan $e t$ al., 2008; Frohlich, 2013). In addition, some NPs do not raise directly ROS production, but are capable under biological 
conditions such as targeting the mitochondrial (Xia et al., 2006; Sharma et al., 2012).
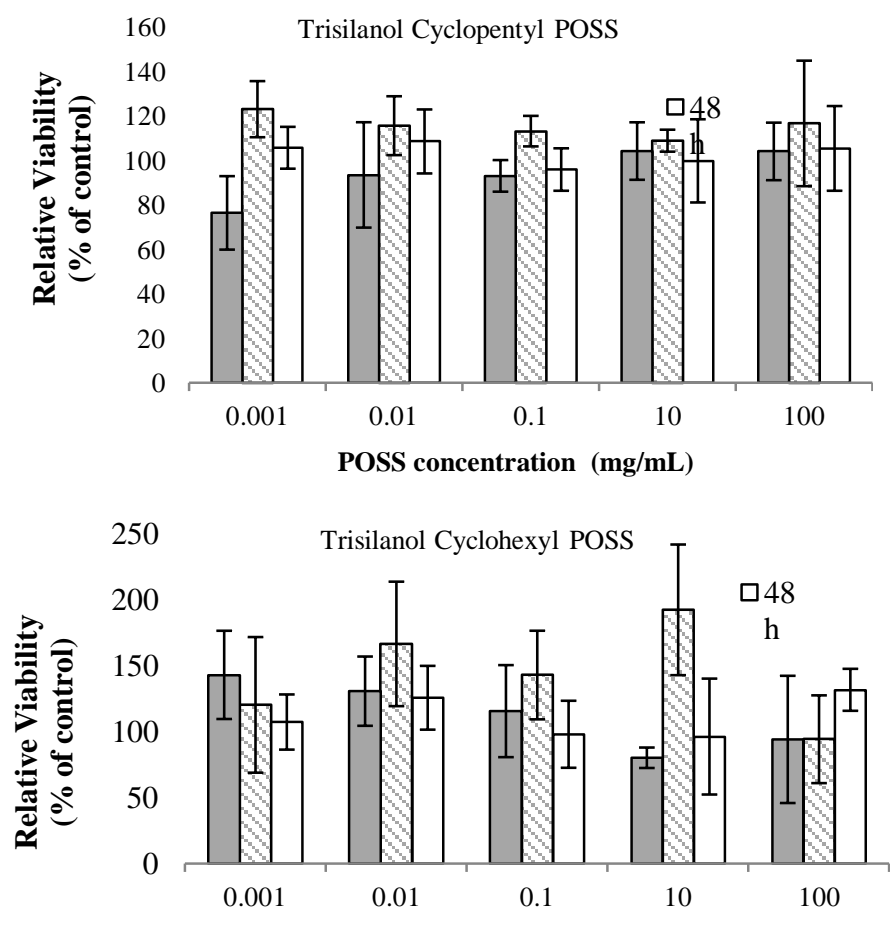

POSS concentration $(\mathrm{mg} / \mathrm{mL})$
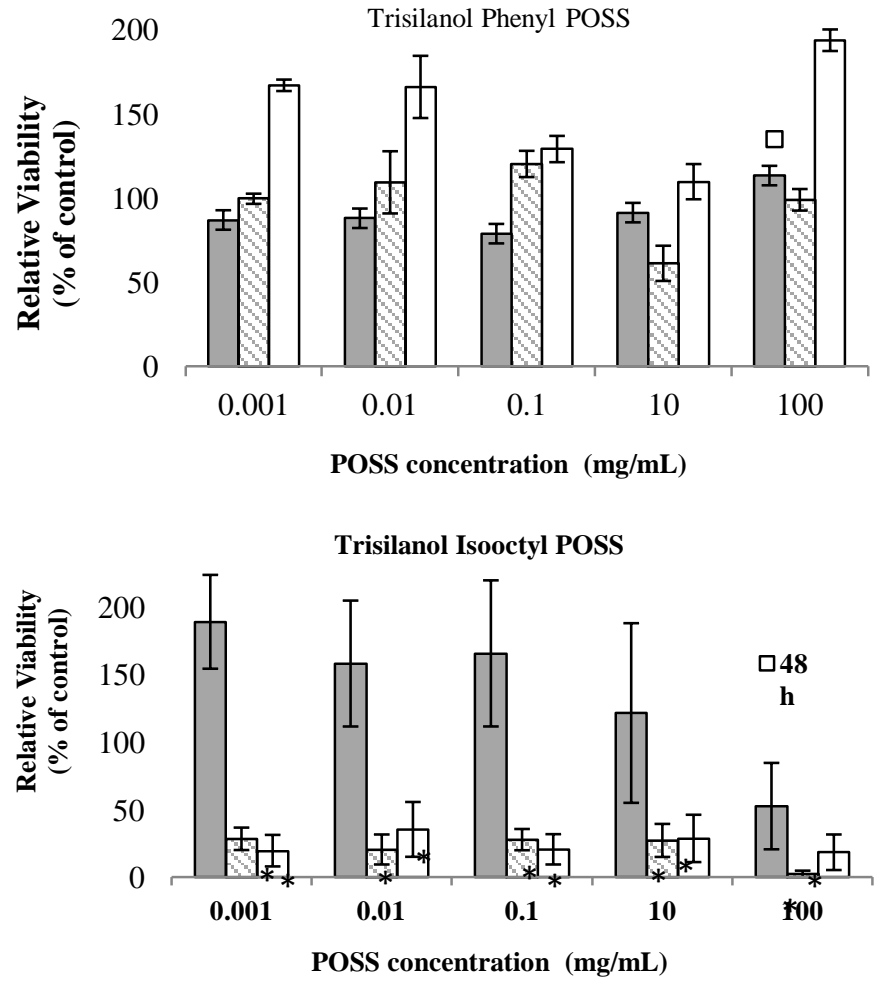

Fig. 1: Metabolic activity of HaCat cell line after exposure to four types of POSS particles. The cells growth significantly decreased after $24 \mathrm{~h}$ exposure to TrisilanolIsooctyl POSS; other POSS particles did not show a growth inhibition compared to untreated control. Data are shown as relative survival (\%) compared to the untreated control and are presented as mean \pm SEM, $n=3$.
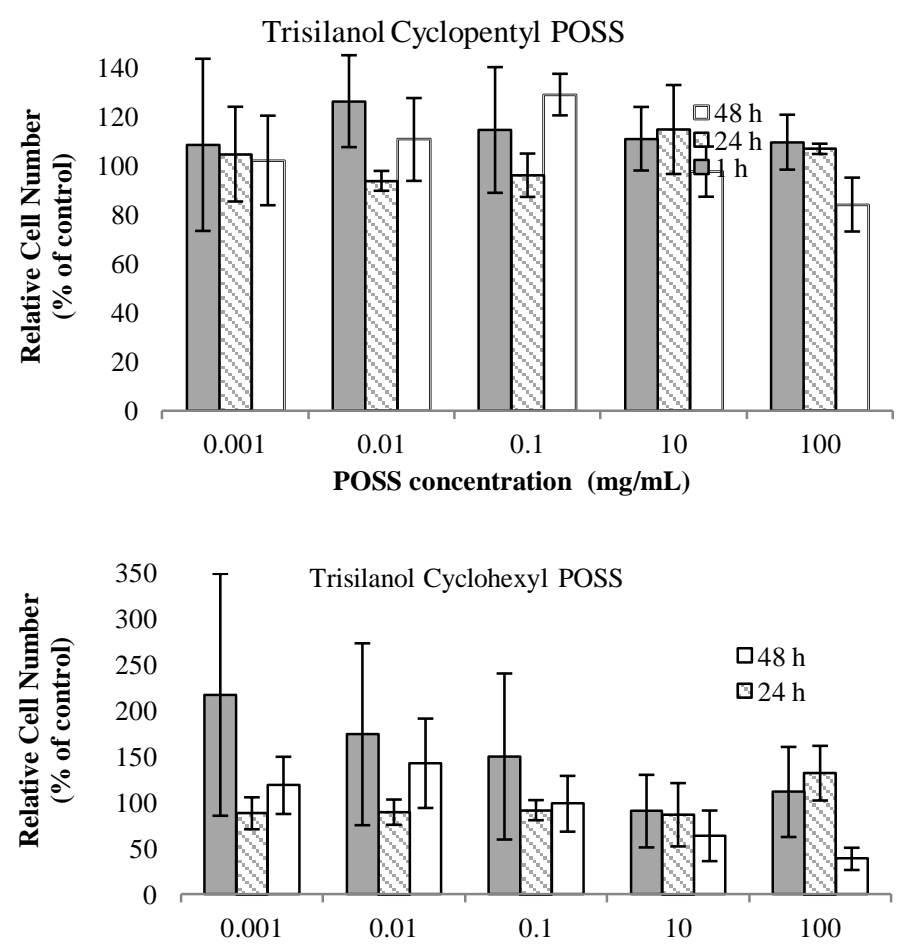

POSS concentration $(\mathrm{mg} / \mathrm{mL})$
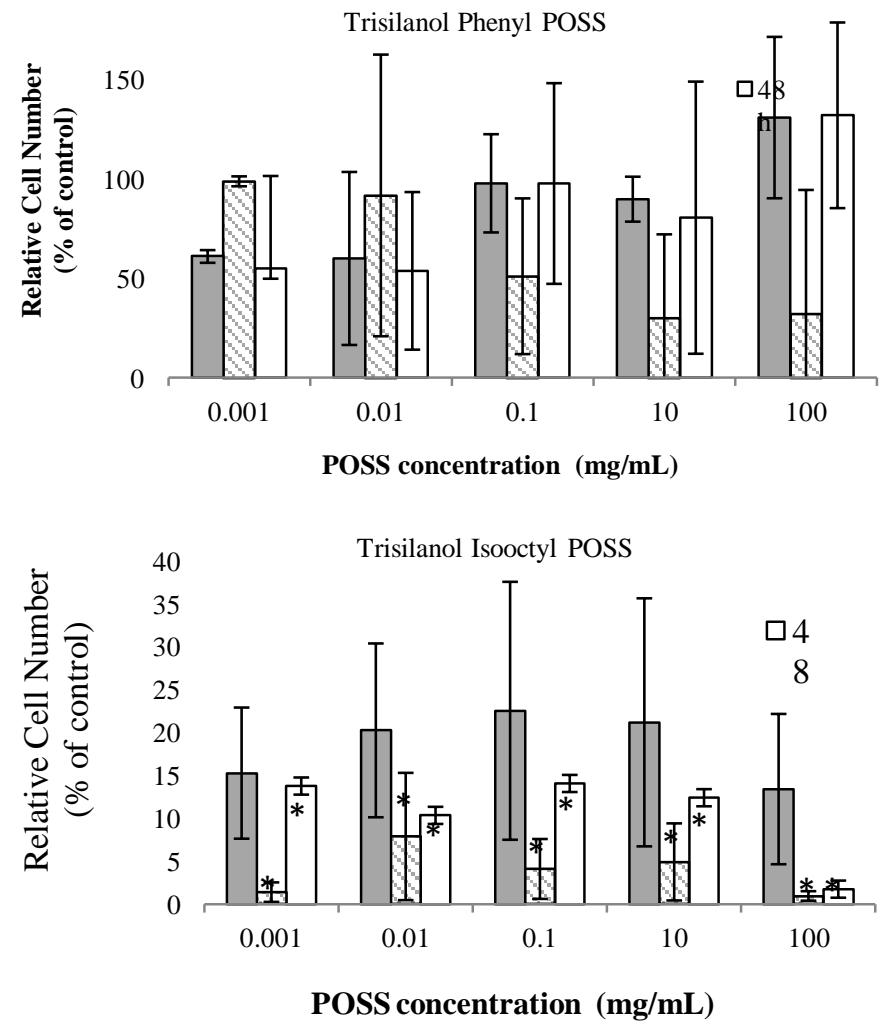

Fig. 2: Treatment of HaCaT cell line with POSS particles assessed using the crystal violet assay. TrisilanolIsooctyl POSS significantly restricted the cell growth after $24 \mathrm{~h}$ exposure. Trisilanol Phenyl and Cyclohexal POSS at high and variable doses showed toxicity to HaCaT cells. Data are shown as relative cell number $(\%)$ compared to the untreated control and are presented as mean \pm $\mathrm{SEM}, \mathrm{n}=3$. 
In figure 2, variable impact observed for Trisilanol, Cyclohexyl, Phenyl and Isooctyl using crystal violet assay. TrisilanolIsooctyl POSS significantly reduced the cell number of HaCaT cells after 24 and $48 \mathrm{~h}$ exposure in all concentrations. The methods that have been used to identify the toxicity of NPs including general toxicity assessment, testing toxicokinetics of NP in humans and animals, in vitro and in vivo assays revealed inconsistent results (Bakand and Hayes, 2016). The source of NPs toxicity can be the particle size, size distribution, shape, surface area and surface chemistry (Kelly et al., 2003, Saptarshi et al., 2013). Therefore, the only way to avoid testing every single NPs and it variant in toxicological test, is to correlate the physicochemical characteristics with their toxicity in a structure activity relationship model (Saptarshi et al., 2013, Balachandran et al., 2005).

\section{CONCLUSION}

Four novel Polyhedral Oligomeric Silsesquioxane (POSS) particles were tested for biocompatibility for a promising application in anti-cancer drug delivery. We previously investigated the interference ofthe four POSS particles and others particles with MTT and crystal violet assay. The interference of these particles was correlatedto some of the physical and chemical properties. Toxicity of the four POSS particles seems to be a shape or size dependent. At $100 \mathrm{~nm}$ size in diameter, only TrisilanolIsooctyl POSS interrupted the metabolic activity also reduce relative cell number of $\mathrm{HaCaT}$ cell line. The other POSS particles did not show any sign of toxicity in both assays although particles were at the same concentrations. Trisilanol Phenyl, Cyclopentyl and Cyclohexal POSS particles could be a potential platform for anti-cancer drug delivery.

\section{ACKNOWLEDGMENT}

Financial support and sponsorship: Authors would like to thank the Ministry of Higher Education, Saudi Arabia, for partial support of this project.

Conflict of Interests: There are no conflicts of interest.

\section{REFERENCE}

Almutary A., Sanderson B. The MTT and Crystal Violet Assays Potential Confounders in Nanoparticle Toxicity Testing. International Journal of Toxicology, 2016; 1091581816648906.

Auffan M. L., Achouak W., Rose J. R., Roncato M. A., Chanéac C., Waite D. T., Masion A., Woicik J. C., Wiesner M. R. \& Bottero J.Y. Relation between the redox state of iron-based nanoparticles and their cytotoxicity toward Escherichia coli. Environmental Science \& Technology, 2008; 42: 6730-6735.

Bakand S., Hayes A. Toxicological considerations, toxicity assessment, and risk management of inhaled nanoparticles. International Journal of Molecular Sciences, 2016; 17, 929.

Balachandran P., Wei F., Lin RC., Khan I. A., Pasco D. S. Structure activity relationships of aristolochic acid analogues: toxicity in cultured renal epithelial cells. Kidney International, 2005; 67, $1797-$ 1805 .
Buonocore, G., Perrone, S., Tataranno, M. L. Oxygen toxicity: chemistry and biology of reactive oxygen species. Seminars in Fetal and Neonatal Medicine, 2010: 186-190.

Chang, Y. N., Zhang, M., Xia, L., Zhang, J. \& Xing, G. The toxic effects and mechanisms of $\mathrm{CuO}$ and $\mathrm{ZnO}$ nanoparticles. Materials, 2012; 5: 2850-2871.

Chiba, K., Kawakami, K., Tohyama, K. Simultaneous evaluation of cell viability by neutral red, MTT and crystal violet staining assays of the same cells. Toxicology In Vitro, 1998; 12, 251258.

El-Badawy, A. M., Silva, R. G., Morris, B., Scheckel, K. G., Suidan, M. T., Tolaymat, T. M. Surface charge-dependent toxicity of silver nanoparticles. Environmental Science \& Technology, 2010; 45, 283-287.

Foldbjerg R., Olesen P., Hougaard M., Dang D. A., Hoffmann, H. J. \& Autrup, H.PVP-coated silver nanoparticles and silver ions induce reactive oxygen species, apoptosis and necrosis in THP-1 monocytes. Toxicology letters, 2009; 190, 156-162.

Frohlich E. Cellular targets and mechanisms in the cytotoxic action of non-biodegradable engineered nanoparticles. Current drug metabolism, 2013; 14, 976-988.

Gao W., Lai J. C., Leung S. Functional enhancement of chitosan and nanoparticles in cell culture, tissue engineering, and pharmaceutical applications. Frontiers in physiology, 2012; 3, 321.

Ghanbari H., Cousins B. G., Seifalian A. M.A nanocage for nanomedicine: polyhedral oligomeric silsesquioxane (POSS). Macromolecular Rapid Communications, 2011a; 32, 1032-1046.

Ghanbari, H., De Mel, A. \& Seifalian, A. M. Cardiovascular application of polyhedral oligomeric silsesquioxane nanomaterials: a glimpse into prospective horizons. Int J Nanomedicine,2011c; 6, 775786.

Grassian, V. H. When size really matters: size-dependent properties and surface chemistry of metal and metal oxide nanoparticles in gas and liquid phase environments $\dagger$. The Journal of Physical Chemistry C, 2008; 112, 18303-18313.

Jain D., Bar-Shalom, D. Alginate drug delivery systems: application in context of pharmaceutical and biomedical research. Drug development and industrial pharmacy, 2014; 40, 1576-1584.

Kelly K. L., Coronado, E., ZHAO, L. L. \& SCHATZ, G. C.The optical properties of metal nanoparticles: the influence of size, shape, and dielectric environment. The Journal of Physical Chemistry $B, 2003$; 107, 668-677.

Kim S., Heo S., Koak J., Lee J., Lee Y., Chung D., Lee J. Hong, S. A biocompatibility study of a reinforced acrylic-based hybrid denture composite resin with polyhedraloligosilsesquioxane. Journal of oral rehabilitation, 2007; 34, 389-395.

Martin C. R. 1994. Nanomaterials--a membrane-based synthetic approach. DTIC Document.

Mosmann T. Rapid colorimetric assay for cellular growth and survival: application to proliferation and cytotoxicity assays. Journal of immunological methods, 1983; 65, 55-63.

Salata O. V. Applications of nanoparticles in biology and medicine. Journal of nanobiotechnology, 2004; 2, 1.

Saptarshi S. R., Duschl A., Lopata A. L. Interaction of nanoparticles with proteins: relation to bio-reactivity of the nanoparticle. Journal of nanobiotechnology, 2013; 11, 1.

Sharma V., Anderson D., Dhawan A. Zinc oxide nanoparticles induce oxidative DNA damage and ROS-triggered mitochondria mediated apoptosis in human liver cells (HepG2). Apoptosis, 2012; 17, 852-870.

Silva G. A. Introduction to nanotechnology and its applications to medicine. Surgical neurology, 2004; 61, 216-220.

Singh N., Jenkins G. J., Asadi R., Doak, S. H.Potential toxicity of superparamagnetic iron oxide nanoparticles (SPION). Nano Reviews \& Experiments, 2010; 1. 
Smith M. L., Murphy K., Doucette C. D., Greenshields A. L., Hoskin D. W. The Dietary Flavonoid Fisetin Causes Cell Cycle Arrest, Caspase-Dependent Apoptosis, and Enhanced Cytotoxicity of Chemotherapeutic Drugs in Triple-Negative Breast Cancer Cells. Journal of cellular biochemistry, 2016.

Wilkinson J. Nanotechnology applications in medicine. Medical device technology, 2003; 14, 29-31.

Xia T., Kovochich M., Brant J., Hotze M., Sempf J., Oberley T., Sioutas C., Yeh J. I., Wiesner M. R., Nel A. E.Comparison of the abilities of ambient and manufactured nanoparticles to induce cellular toxicity according to an oxidative stress paradigm. Nano letters, 2006; 6, 1794-1807.

\section{How to cite this article:}

Almutary A, Sanderson B. Toxicity of four novel Polyhedral Oligomeric Silsesquioxane (POSS) particles used in anti- cancer drug delivery. J App Pharm Sci, 2017; 7 (02): 101-105. 